

Turkish Studies - Comparative Religious Studies

\title{
İlahiyat Fakültesi Öğrencilerinin Epistemolojik İnanç Düzeyi (Bolu Abant izzet Baysal Üniversitesi İlahiyat Fakültesi Örneği)
}

\author{
Epistemological Belief Level Of The Students Of The Faculty Of Theology (In Case Of Bolu Abant \\ Izzet Baysal University Theology Faculty)
}

\author{
Seyyid Sancak ${ }^{*}$ Kevser Özevin ${ }^{* *}$
}

\begin{abstract}
The aim of this study is to determine the level of epistemological belief in learning by the undergraduate students of the Faculty of theology and to examine the epistemological beliefs of the students in terms of certain variables. The research in the relational scanning model was carried out with the participation of 371 students who were studying for a bachelor's degree in the Faculty of theology. The research's data collection tool was developed by Sing-Chai, Teo and Beng-Lee (2009) and adapted into Turkish by Kutluca, Soysal and Radmard (2018). The data collection tool consists of two parts," epistemological beliefs scale " and "Personal Information Form". Students ' scientific epistemological beliefs to determine their level of sub-dimensions, the average of (X) and standard deviation (SD) scores, calculated variables such as gender of the parameters of two independent groups $\mathrm{t}$-test; three or more variable parameters, such as age group and grade level with one way analysis of variance (Anova) using the statistical conclusions were reached. In addition, the Tukey test was used to determine the difference between the groups. According to the results obtained, it is possible to say that the epistemological belief levels of the students of the Faculty of theology are improved. As a result of the research, there was a significant difference between the level of prep school students who started school and the level of epistemological belief in learning in later classes. It has also been found that the sexes and class levels of the students influence the lower dimensions of the students ' scientific epistemological beliefs.
\end{abstract}

Structured Abstract: In most recent studies, epistemological beliefs show a significant determinant effect on learning. For example, it has been revealed that university students' epistemological beliefs about their attitudes towards school and their beliefs towards the benefit of education have important effects on the thinking of the epistemological beliefs of the university students on their cognitive processing of their epistemological beliefs in the process of learning new information and how much they internalize this information.(Deryakulu and Büyüköztürk, 2005; see also Schommer,1990; Schommer and Walker 1993).

\footnotetext{
* Dr. Öğr. Üyesi, Bolu Abant İzzet Baysal Üniversitesi, İlahiyat Fakültesi, Felsefe ve Dinbilimleri Bölümü Asst. Prof. Dr., Bolu Abant Izzet Baysal University, Faculty of Theology, Department of Philosophy and Religious Sciences

ORCID 0000-0003-0206-0237

seyyidsancak@ibu.edu.tr

** Yüksek Lisans Öğrencisi, Gazi Üniversitesi, Eğitim Bilimleri Enstitüsü, Eğitim Teknolojisi Bölümü

Graduate student, Gazi University, Institute of Education Sciences, Educational Technology Department ORCID 0000-0001-7536-734X

kvsrozvn@gmail.com

Cite as/ Atıf: Sancak, S. \& Özevin, K. (2020). İlahiyat fakültesi öğrencilerinin epistemolojik inanç düzeyi (Bolu Abant İzzet Baysal Üniversitesi İlahiyat Fakültesi örneği). Turkish Studies - Religion, 15(3), 425-436. https://dx.doi.org/10.47091TurkishStudies.43260

Received/Geliş: 30 April/Nisan 2020

Accepted/Kabul: 20 September/Eylül 2020

Copyright $($ INTAC LTD, Turkey

Checked by plagiarism software

Published/Yayın: 25 September/Eylül 2020

CC BY-NC 4.0
} 
From this point students with advanced epistemological beliefs;

Use a higher number of more qualified cognitive information processing strategies when we observe the learning process.

In the metacognitive framework, students more frequently and accurately supervise the extent to which they can learn teaching materials. have higher quality, higher level of academic achievement, and have more positive attitudes about the school. strongly believe in the benefits of education and are able to produce deep and multifaceted thoughts that are difficult to solve, which we can call more complex. (Deryakulu and Büyüköztürk, 2005).

Based on this framework, we aim to determine the scientific epistemological belief levels of our students and to contribute to the studies in the field by examining their epistemological beliefs in terms of some variables with the study titled epistemological belief level of theology faculty students. However, we can not say that there are much study in the context of religious education and epistemology or theology faculties and epistemology. Examples of the current studies are Faruk Karaca and Zeynep Özcan's "A Research on the Relationship Between Academic Motivation and Psychological Well-being in the Faculty of Theology Students" published in the İlahiyat Tetkikleri Dergisi and Emin Çelebi's "Epistemological Possibility of the Applicability of Constructivist Approach in the Teaching of Religion and Morality" published in the Sosyal Bilimler Araştırmaları Dergisi. In order to determine the epistemological belief level of the students of the Faculty of theology, the following questions were answered:

1. Is there a significant difference between the genders of the Faculty of Theology undergraduates and their epistemological belief levels?

2. Is there a significant difference between the ages of the undergraduate students of the Faculty of Theology and their epistemological belief levels?

3.Is there a significant difference between the grade levels of the Faculty of theology undergraduates and their epistemological belief levels?

\section{Method}

In the study, the levels of epistemological beliefs of the students of the Faculty of Theology have been tried to be determined. For this purpose, the change of students' epistemological beliefs according to class level, gender and age was determined. In order to achieve this goal, descriptive and relational scanning models from quantitative research methods were used. The target population of the study is students who are studying at Bolu Abant İzzet Baysal University, Faculty of Theology, in the fall semester of the 2019-2020 academic year. The sample of the study consists of 371 students studying at the Faculty of Theology at Abc University in the fall semester of the 2019-2020 academic year. The sample of the study consists of 371 students studying at the Faculty of Theology at Abant İzzet Baysal University in the fall semester of the 2019-2020 academic year. The sample-set was chosen randomly, thus ensuring that the results of the research are the closest to the truth.. The target population group and the working group are groups of similar-purpose clusters with various elements. (Karasar, 1999, p.114). In our study, the epistemological beliefs scale for learning, developed by Sing-Chai, Teo and Beng-Lee (2009) and later adapted to Turkish by Kutluca, Soysal and Radmard (2018), was used. This scale used is a 5-point Likert scale questionnaire with 23 questions.

In addition to the Likert-type survey questions, the personal information questionnaire was used where demographic information of the participants was also taken. In this context, in order to achieve the result of the research, gap analysis were used. Bivariate parameters such as gender were analyzed using the independent groups $t$ test, while parameters with more than two variables such as age group and grade level were analyzed using one-way variance analysis. In addition, tukey test was used to detect the difference between groups. test was used for. Also during the analyses, P significance level was accepted as 05.

\section{Results and İnterpretations}

Students who are studying in the Faculty of Theology of given variables varies according to the levels of epistemological beliefs. At the level of epistemological beliefs than male students have a higher score than female students, while male students had lower scores than the conclusion reached. This ultimately contributed to the formation of the group the majority of female students.

As a result of the research, the prep school level students who are studying in the Faculty of Theology in progressive classrooms for learning when they start with there was a significant difference between the levels of epistemological beliefs. The Faculty of theology the Faculty of Theology of education that illustrates this 
situation for the learning of their students contributes in the direction of increasing the level of epistemological beliefs.

The results of the analysis are shown in Table 5, with the ages of the students it has been found that there are significant differences between epistemological beliefs towards learning. The results of the analysis, according to students 18 years of age and 30 years of age the levels of epistemological beliefs for learning are lower, while the levels of epistemological beliefs for the learning of other students in the age range was found to be higher. Students new to the school generally consist of students 18 years of age. Table 7 students ' levels of epistemological beliefs for learning and the results were analyzed by grade level are given. Here its low level of epistemological beliefs for student learning has been found to be effective and they begun their education of the students in the seminary who caused it are believed to be. Over the age of 30 students ' epistemological belief that learning is the main reason for low levels in other age groups can be explained by the theory of generations.

\section{Conclusion and Recommendations}

The results of our researches provide information about the epistemological beliefs of the students of the Faculty of Theology and their perspectives on learning and knowledge. With reference to this study:

1. The way the students learn and their perspectives on learning influence the methods, strategies and processing of the course to be presented to them. The results of this research can also be used to investigate the teaching methods and techniques that the faculty members of the Faculty of Theology will use in the course and what new teaching methods and techniques may be intended to be designed.

2. In addition, manners of faculty members of the Faculty of Theology towards the teaching lesson can be examined.

3. Depending on the epistemological beliefs of the students of the Faculty of Theology, the program can be changed or restructured for student needs and student profile in the program prepared and presented. Accordingly, students' opinions regarding the curriculum and program of the Faculty of Theology can be received.

4. In our research, only students of the Faculty of Theology were included as working groups. With a study to be carried out with other faculties, the results of these faculties towards epistemological belief levels can be compared.

5. Significant differences were found between the genders of the students and their epistemological belief levels. The reason for this can be examined using the results of the research.

Keywords: Religious Education, Epistemology, Epistemological Beliefs Scale, İnformation, Learning

Öz: $\mathrm{Bu}$ çalışmanın amacı ilahiyat fakültesi lisans öğrencilerinin öğrenmeye yönelik epistemolojik inanç düzey durumlarını tespit etmek ve öğrencilerin öğrenmeye yönelik epistemolojik inançlarını belli değişsenler açısından irdelenmesidir. İlişkisel tarama modelindeki araştırma ilahiyat fakültesinde lisans eğitimi almakta olan 371öğrencinin katılımıyla gerçekleştirilmiştir. Araştırmanın veri toplama aracı Sing-Chai, Teo ve BengLee (2009) tarafından geliştirilmiş ve daha sonra Kutluca, Soysal ve Radmard (2018) tarafından Türkçe'ye uyarlanmış olan "Epistemolojik İnançlar Ölçeği” ile "Kişisel Bilgi Formu" olarak iki bölümden oluşmaktadır. Öğrencilerin bilimsel epistemolojik inanç düzeylerini belirlemek için; alt boyutların ortalama (X) ve standart sapma (SS) puanları hesaplanmış, cinsiyet gibi iki değişkenli parametreler bağımsız gruplar t testi ile yaş grubu ve sınıf düzeyi gibi üç ve daha fazla sayıda değişkene sahip parametreler ise tek yönlü varyans analizi (anova) kullanılarak analiz edilmiş ve bu şekilde istatistiki sonuçlara ulaşılmıştır. Ek olarak, gruplar arasında oluşan farkın tespit edebilmek için de tukey testi kullanılmıştır. Elde edilen sonuçlara göre, ilahiyat fakültesi öğrencilerinin epistemolojik inanç düzeylerinin gelişmiş olduğunu söylemek mümkündür. Bununla beraber yapılan araştırma sonucunda ilahiyat fakültesinde öğrenim görmekte olan öğrencilerin okula başladıkları hazırlık sınıfı ile ilerleyen sınıflardaki öğrenmeye yönelik epistemolojik inanç düzeyleri arasında anlamlı bir fark olduğu ve öğrencilerin cinsiyetlerinin ve sınıf düzeylerinin, öğrencilerin bilimsel epistemolojik inançlarının alt boyutlarını etkilediği de tespit edilmiştir.

Anahtar Kelimeler: Din Eğitimi, Epistemoloji, Epistemolojik İnançlar Ölçeği, Bilgi, Öğrenme 


\section{Giriş}

Felsefenin ilgi duyduğu ve çalışma konusu yaptığı önemli alanlardan biri epistemolojidir. Terim olarak epistemolojinin manasına baktığımız da Yunanca episteme (bilgi) ve logos (açıklama, anlam) kelimelerinden meydana gelmiştir. Son dönemlerde epistemoloji sadece felsefenin değil aynı zamanda eğitim ve psikolojinin de ilgi duyduğu bir alan haline gelmiştir. Eğitim açısından epistemoloji ele alındığında; bilginin tanımlanma, yapılandırılma, değerlendirme ve bilmenin gerçekleşme sürecine ilişkin durumları ve inançları da kapsadığı anlaşılmaktadır (Başbay,2013). Diğer bir ifadeyle epistemolojik inanç, bireyin bilgi ve öğrenmeye yönelik inancı şeklinde de tanımlanabilir (Demir ve Akınoğlu, 76). Özellikle epistemolojik inançların yaşam boyu öğrenme de olduğu gibi eğitim süreci içerisinde bireyin bilgiyi elde etmesini ve yapılandırılmasını etkilemektedir. Dolayısıyla öğrencilerin akademik performanslarını ve bilgiye sahip olmalarını etkileyen en önemli unsurlardan biri, onların bilgiye yönelik inançlarıdır ve bu durum diğer öğrenme çıktılarıyla bağlantılıdır (Başbay,2013).

Yakın zamana kadar ortaya konulan çoğu araştırma epistemolojik inançların öğrenme üzerinde önemli derecede belirleyici etkisi olduğunu göstermiştir. Örneğin; üniversite öğrencilerinin epistemolojik inançlarının yeni bilgileri öğrenme sürecinde bilişsel olarak işlemeleri ve bu bilgileri ne seviyede içselleştirdiklerini denetlemeleri, okul hakkındaki tutumları, eğitimin faydasına yönelik inançları hususunda ve düşünme formları üzerinde önemli etkileri olduğu ortaya konulmuştur. (Deryakulu ve Büyüköztürk, 2005; bkz:Schommer,1990; Schommer ve Walker 1993).

Bu noktadan hareketle gelişmiş epistemolojik inançlara sahip öğrenciler;

- $\quad$ Öğrenme sürecini gözlemlediğimizde yüksek sayıda ve daha nitelikli bilişsel bilgi işleme stratejilerini kullanırlar.

- $\quad$ Meta bilişsel çerçevede öğretim materyallerini ne ölçüde öğrenebildiklerini daha sıklıkla ve doğru bir şekilde denetlemektedirler.

- Daha kaliteli, üst seviyede akademik başarı göstermekte, okul hakkında daha pozitif tutumlara sahiptirler.

- $\quad$ Eğitimin faydasına güçlü bir şekilde inanmakta ve daha karmaşık diyebileceğimiz, çözümü güç olan, derin ve çok yönlü düşünceler üretebilmektedirler (Deryakulu ve Büyüköztürk, 2005).

Eğitim alanında çalışan pek çok araştırmacı, eğitim sürecine katılan bireylerin bilgiye ve bilmeye yönelik anlamalarını, idraklerini nasıl geliştirdiklerine ve bu anlam ve idrakleri, nasıl ve ne şekilde hayata geçirdiklerine yoğunlaşmaktadırlar (Kutluca vd, 2018). Özellikle bilginin tanımlanması, yapılandırılması, değerlendirilmesi ve meydana gelme-gerçekleşme süreci, öğretmen eğitimi açısından kritik önem arz etmektedir. Biz biliyoruz ki bilginin doğası ve kaynağıyla bağlantılı olarak ön kabulleri olan epistemolojik inançlar; öğretmen adaylarının başta akademik performansları olmak üzere; öğrenme stratejilerini, sınıf yönetimi ve sınıf içi davranışlarını, üst bilişsel becerilerini, bilgiyi anlama ve yorumlama kalıplarını ve okulla alakalı tutumlarına etkide bulunmaktadır (Kutluca vd, 2018; bkz: Topçu, 2011).

Sonuç olarak modern dünyada bilim, bilgi ve bilimsel düşünce ile ilgili olarak ortaya çıkan yeni anlayışlar, hazırlanan eğitim programlarını etkilemiştir. Özellikle, bilimsel bilginin oluşum süreci ve bu oluşum sürecinde yer alan ve bu sürece katkıda bulunan bilim insanlarının vasıflarının ne olduğuna yönelik yeni standartlar belirlenmiştir. $\mathrm{Bu}$ standartlar, ülkemizdeki eğitim programlarında da kendine yer bulmuştur. (Yenice ve dgr, 2018; bkz: MEB, 2010). Modern dünyada öğrencilerin bilimi özümseyerek içselleştiren, yaşamlarında kullanabilen bireyler olarak yetişmelerinin önemi giderek artmakta bu sebeple öğrencilerin bilimsel bilgileri öğrenme ve 
edinme aşamasında; bilim yaklaşımı ve anlayışındaki farklılaşmanın dikkate alınması gerekmektedir. Epistemolojik inançlar bağlamında modern dünyada öğrenciler bilginin kaynağına, araçlarına, alanına, kapsamına, sınırlarına ve doğru bilginin doğruluk derecesine yönelik sorgulama yapabilmekte, tutum ve davranışlarını bu bağlamda sergileyebilmektedirler (Yenice ve dgr, 2018; Demir, 2009).

Bu çerçeveden hareketle bizde "İlahiyat Fakültesi Öğrencilerinin Epistemolojik İnanç Düzeyi (Baibü İlahiyat Fakültesi Örneği)" isimli çalışma ile öğrencilerimizin bilimsel epistemolojik inanç düzeylerini belirlemek ve epistemolojik inançlarını bazı değişkenler açısından inceleyerek alanda yapılan çalışmalara katkıda bulunmayı hedefliyoruz. Bununla beraber din eğitimi ve epistemoloji ya da ilahiyat fakülteleri ve epistemoloji bağlamında çok fazla çalışmanın mevcut olmadığını söyleyebiliriz. Mevcut yapılmış olan çalışmalara Faruk Karaca ve Zeynep Özcan'ın İlahiyat Tetkikleri Dergisi’nde yayınlanan “İlahiyat Fakültesi Öğrencilerinde Akademik Motivasyon ile Psikolojik İyi Oluş İlişkisi Üzerine Bir Araştırma" ve Emin Çelebi'nin Sosyal Bilimler Araştırmaları Dergisi'nde yayınlanan "Yapılandırmacı Yaklaşımın Din ve Ahlâk Öğretiminde Uygulanabilirliğinin Epistemolojik İmkanı" isimli çalışmaları örnek olarak verilebilir.

Araştırmada ilahiyat fakültesi öğrencilerinin epistemolojik inanç düzeyini belirlemek amaciyla şu sorulara cevap aranmıştır;

1. İlahiyat fakültesi lisans öğrencilerinin cinsiyetleri ile epistemolojik inanç düzeyleri arasında anlamlı bir fark var midır?

2. İlahiyat fakültesi lisans öğrencilerinin yaşları ile epistemolojik inanç düzeyleri arasında anlamlı bir fark var midır?

3. İlahiyat fakültesi lisans öğrencilerinin sınıf düzeyleri ile epistemolojik inanç düzeyleri arasında anlamlı bir fark var mıdır?

\section{Yöntem}

2019 yılında yapılan araştırmada ilahiyat fakültesi öğrencilerinin öğrenmeye yönelik epistemolojik inanç düzeyleri belirlenmeye çalışılmıştır. Bu amaç doğrultusunda öğrencilerin öğrenmeye yönelik epistemolojik inançlarının sınıf düzeyi, cinsiyet ve yaşa göre değişimi tespit edilmiştir. $\mathrm{Bu}$ amacı gerçekleştirebilmek için nicel araştırma yöntemlerinden betimsel ilişkisel tarama modeli kullanılmıștır. Sosyal bilimler ve fen bilimlerinde en çok kullanılan araștırma yöntemlerinden biri, nicel araştırma yöntemidir. Nicel araştırma yöntemi realizmin bilimdeki yansıması olan pozitivizmden etkilenmiştir. Bu demek oluyor ki nicel araştırma yöntemleri, gerçeği olduğu gibi aktaran, insandan bağımsız ve tek gerçeğin açığa çıkarılmasına dayalı yöntemdir (Yıldırım, 1999). Nicel araştırma yöntemi farklı analiz ve modelleri kapsamaktadır. Betimsel analizler, farklı veri toplama teknikleri ile elde edilen veriler aracılığ ile bir durumu aydınlatmak, değerlendirmek ve yorumlamayı içerir (Yıldırım ve Şimşek, 2003). Betimsel analizlerde asıl amaç durumu etraflıca açıklamak ve tanımlamaktır.

Araştırmanın evreni Bolu Abant İzzet Baysal Üniversitesi İlahiyat Fakültesi’nde 20192020 eğitim-öğretim yılı güz dönemi fakültede öğrenim görmekte olan öğrencilerden oluşmaktadır. Araştırmanın örneklemini ise Bolu Abant İzzet Baysal Üniversitesi İlahiyat Fakültesinde 20192020 eğitim-öğretim yılı güz dönemi fakültede öğrenim görmekte olan 371 öğrenci oluşturmaktadır. Örneklem kümesi tesadüfî olarak seçilmiş, böylece araştırma sonucunun gerçeğe en yakın sonucu vermesi sağlanmaya çalışılmıştır. Evren ve çalışma grubu, içinde çeşitli elemanları olan, benzer amaçlı (işlevli) kümelerden oluşan gruplardır (Karasar, 1999, s.114). Araştırmamızda Sing-Chai, Teo ve Beng-Lee (2009) tarafından geliştirilen daha sonra Kutluca, Soysal ve Radmard (2018) tarafindan Türkçeye uyarlaması yapılan öğrenmeye yönelik epistemolojik inançlar ölçeği kullanılmıştır. Kullanılan bu ölçek 23 soruluk 5'li likert tipi bir ölçektir. Likert tipi ölçekler araştırılan konu hakkında katılımcıların katılma düzeylerini belirten seçenekler aracıllı̆ı ile veri 
toplamak amacıyla kullanılmaktadır. Likert tipi ölçeklerde, katılımcıların katılma düzeyleri 3,5,7’li dereceler ile ifade edilebilir ve iki aşırı uç arasında yer alan seçenekler katılımcılara sunulur (Turan, Şimşek, Aslan, 2015). Bu araştırmada da 5'li likert tipi ölçek kullanılmış olup, katılımcılara "kesinlikle katılmiyorum, katılmıyorum, kararsızım, katılıyorum ve kesinlikle katılıyorum" şeklinde seçenekler sunulmuştur. Likert tipi ölçek maddelerinin dışında katılımcıların demografik bilgilerinin de alındığı kişisel bilgiler anketi kullanılmıştır. Bu bağlamda araştırma sonucuna ulaşılması amacıyla farklılık analizleri kullanılmıştır.

Cinsiyet gibi iki değişkenli parametreler bağımsız gruplar $\mathrm{t}$ testi ile analiz edilirken, yaş grubu ve sınıf düzeyi gibi ikiden fazla sayıda değişkene sahip parametreler ise tek yönlü varyans analizi (anova) kullanılarak analiz edilmiştir. Ek olarak, ikiden fazla sayıda alt gruba sahip değişkenlerde farklılığın kaynağını tespit edebilmek için de tukey testi kullanılmıştır. Yapılan analizler sırasında, $p$ anlamlılık düzeyi 0.5 olarak kabul edilmiştir. Tüm bu işlemler sonucunda ulaşılan araştırma bulguları aşağıda sunulmuştur.

\section{Demografik Bilgiler}

Bu araştırma, Bolu Abant İzzet Baysal Üniversitesi İlahiyat Fakültesi’nde 2019-2020 güz döneminde öğrenimlerine devam etmekte olan 371 öğrencinin katılımı ile yürütülmüştür. Araştırmaya katılan öğrencilerin demografik bilgilerine yönelik toplanan verilere ait frekans ve yüzdelik dağılım Tablo 1'de gösterilmiştir.

Tablo 1: Örneklem Grubunun Cinsiyete Dayalı Frekans ve Yüzdelik Dağılım Sonuçları

\begin{tabular}{lll}
\hline Cinsiyet & F & \% \\
\hline Erkek & 95 & 25.6 \\
Kadın & 276 & 74.4 \\
\hline Toplam & 371 & 100.0 \\
\hline
\end{tabular}

Tablo 1'te ankete katılan ve araştırmanın örneklem grubunu oluşturan ilahiyat fakültesi öğrencilerinin yaş bilgileri verilmektedir. Alınan verilere göre; öğrencilerin \%25.6's1 erkek, \%74.4'ü ise kadın katılımcıdan oluşmaktadır.

Tablo 2: Örneklem Grubunun Yaş Grubuna Dayalı Frekans ve Yüzdelik Dağglım Sonuçları

\begin{tabular}{lll}
\hline Yaş Grubu & F & \% \\
\hline 18 alt1 & 22 & 5.9 \\
$19-22$ & 63 & 17.0 \\
$23-25$ & 240 & 64.7 \\
$26-39$ & 18 & 4.9 \\
30 üzeri & 28 & 7.5 \\
\hline Toplam & 371 & 100.0 \\
\hline
\end{tabular}

Tablo 2'de ankete katılan ve araştırmanın örneklem grubunu oluşturan ilahiyat fakültesi öğrencilerinin yaş bilgileri verilmektedir. Alınan sonuçlara göre; öğrencilerin \%5.9'u 18 yaş altı, \%17'si 19-22 yaş, \%64.7'i 23-25 yaş, \%4.9'u 26-29 yaş ve \%7.5'i ise 30 üzeri yaş grubunda yer almaktadir.

Tablo 3: Örneklem Grubunun Sınıf Düzeyine Dayalı Frekans ve Yüzdelik Dağılım Sonuçları

\begin{tabular}{lll}
\hline Sınıf Düzeyi & F & \% \\
\hline Hazırlı & 41 & 11.1 \\
1. Sinıf & 41 & 11.1 \\
2. Sinıf & 126 & 34.0 \\
3. Sinıf & 113 & 30.5 \\
4. Sinıf & 50 & 13.5 \\
\hline Toplam & 371 & 100.0 \\
\hline
\end{tabular}

Tablo 3'te ankete katılan ve araştırmanın örneklem grubunu oluşturan ilahiyat fakültesi öğrencilerinin sınıf düzeyleri verilmektedir. Buna göre öğrencilerin \%11.1'inin hazırlık sınıfında, 
$\% 11.1$ 'inin 1. sinıfta, \%34'ünün 2. sinıfta, $\% 30.5$ 'inin 3. sinıfta ve $\% 13.5$ 'inin ise 4 . sinıfta öğrenim gören öğrencilerinden oluşmaktadır.

\section{Bulgular ve Yorumlar}

Araştırma amacı kapsamında Bolu Abant İzzet Baysal Üniversitesi İlahiyat Fakültesi'nde 2019-2020 güz döneminde öğrenim görmekte olan öğrencilerin epistemolojik inançları, cinsiyete dayalı olarak karşılaştırılmıştır. Yapılan analiz sonucunda ulaşılan bulgular, Tablo 4'te sunulmuştur.

Tablo 4: İlahiyat Fakültesi Öğrencilerinin Epistemolojik İnançlarının Cinsiyete Dayalı Kıyaslanmasına Yönelik Bağımsız Gruplar t Testi Sonuçları

\begin{tabular}{lcccccc}
\hline & $\mathbf{N}$ & $\overline{\boldsymbol{x}}$ & $\mathbf{s s}$ & $\mathbf{s d}$ & $\mathbf{T}$ & $\boldsymbol{P}$ \\
\hline Erkek & 95 & 3.39 & .44 & & & .01 \\
Kadin & 276 & 3.52 & .38 & & & \\
\hline
\end{tabular}

Tablo 4'e göre; ilahiyat fakültesinde öğrenim görmekte olan kadın öğrencilerin epistemolojik inançları, erkek öğrencilerin epistemolojik inançlarından daha yüksektir. Bağımsız gruplar t testi sonuçları incelendiğinde, gruplar arasında oluşan bu farkın anlamlı düzeyde olduğu tespit edilmiştir [ $\left.\mathrm{t}_{369}=-2.64, p=.01\right]$. Bu sonuç göstermektedir ki cinsiyet, öğrencilerin öğrenmeye yönelik epistemolojik inançları üzerinde etkili olmaktadır. Bunun sebepleri araştırmamızın kapsamını aşmaktadır fakat araştırma sonuçları ilerde yapılacak araştırmalar için kaynaklık edecektir.

Araştırma amacı kapsamında, ilahiyat fakültesinde öğrenim görmekte olan öğrencilerin epistemolojik inançları yaş grubuna dayalı olarak kıyaslanmıştır. Analizler sonucunda ulaşılan betimsel istatistikler Tablo 5 'te sunulmuş̧ur.

Tablo 5: İlahiyat Fakültesi Öğrencilerinin Epistemolojik İnançlarının Yaş Grubuna Yönelik Karşılaştırılmasına Ait Betimsel İstatistikler

\begin{tabular}{llll}
\hline & N & $\overline{\boldsymbol{x}}$ & Ss \\
\hline 18 altı & 22 & 3.09 & .37 \\
$19-22$ & 63 & 3.49 & .44 \\
$23-25$ & 240 & 3.56 & .35 \\
$26-29$ & 18 & 3.36 & .46 \\
30 üzeri & 28 & 3.21 & .38 \\
\hline \multirow{2}{*}{ Toplam } & \multirow{2}{*}{371} & 3.48 & .40 \\
\hline
\end{tabular}

Tablo 5'e göre ilahiyat fakültesinde öğrenim görmekte olan öğrencilerin epistemolojik inançları yaş grubuna yönelik kıyaslandığında farklılık göstermektedir. Gruplar arasında oluşan bu farkın anlamlı olup olmadığını belirleyebilmek için tek yönlü varyans analizi (anova) yapılmış ve ulaşılan bulgular Tablo 6'da sunulmuştur.

Tablo 6: İlahiyat Fakültesi Öğrencilerinin Epistemolojik İnançlarının Yaş Grubuna Yönelik Karşılaştırılmasına Ait Tek Yönlü Varyans Analizi (Anova) Sonuçları

\begin{tabular}{lllll}
\hline & $\begin{array}{l}\text { Kareler } \\
\text { Toplamı }\end{array}$ & Df & Kareler \\
Ortalaması & F & \multirow{2}{*}{1.83} & \\
Gruplararası & 7.31 & 4 & .14 & 13.09 \\
Grupiçi & 51.05 & 366 & & .000 \\
\hline Toplam & 58.36 & 370 & & \\
\hline
\end{tabular}


Tablo 6'ya göre, ilahiyat fakültesinde öğrenim görmekte olan öğrencilerin epistemolojik inançları, yaş grubuna dayalı olarak karşılaştırıldığında anlamlı bir farklılık göstermektedir $\left[\mathrm{F}_{(4,366)}=13.09, p=.000\right]$. Tukey testi sonuçları incelendiğinde, 18 altı ve 30 üzeri yaş grubundaki öğrencilerin epistemolojik inançları 19-22 ve 23-25 yaş grubundaki öğrencilerin epistemolojik inançlarından anlamlı düzeyde düşük olduğu tespit edilmiştir.

Araştırma amacı kapsamında, ilahiyat fakültesinde öğrenim görmekte olan öğrencilerin epistemolojik inançları sınıf düzeyine dayalı olarak kıyaslanmıştır. Analizler sonucunda ulaşılan betimsel istatistikler Tablo 7'de sunulmuştur.

Tablo 7: İlahiyat Fakültesi Öğrencilerinin Epistemolojik İnançlarının Sınıf Düzeyine Yönelik Karşılaştırılmasına Ait Betimsel İstatistikler

\begin{tabular}{llll}
\hline & $\mathbf{N}$ & $\overline{\boldsymbol{x}}$ & Ss \\
\hline Hazırlik & 41 & 3.10 & .41 \\
1. Sinıf & 41 & 3.09 & .27 \\
2. Sinif & 126 & 3.64 & .35 \\
3. Sinif & 113 & 3.54 & .29 \\
4. Sinif & 50 & 3.62 & .40 \\
\hline Toplam & 371 & 3.48 & \\
\hline
\end{tabular}

Tablo 7'ye göre ilahiyat fakültesinde öğrenim görmekte olan öğrencilerin epistemolojik inançları sınıf düzeyine yönelik kıyaslandığında farklılık göstermektedir. Gruplar arasında oluşan anlamlı farklılı̆̆ belirleyebilmek için tek yönlü varyans analizi (anova) yapılmış ve ulaşılan bulgular Tablo 8'de sunulmuştur.

Tablo 8: İlahiyat Fakültesi Öğrencilerinin Epistemolojik İnançlarının Sınıf Düzeyine Yönelik Karşılaștırılmasına Ait Tek Yönlü Varyans Analizi (Anova) Sonuçları

\begin{tabular}{lllll}
\hline & $\begin{array}{l}\text { Kareler } \\
\text { Toplamı }\end{array}$ & Df & $\begin{array}{l}\text { Kareler } \\
\text { Ortalaması }\end{array}$ & F \\
\hline Gruplar arası & 16.60 & 4 & 4.15 & \multirow{2}{*}{3} \\
Grup içi & 41.76 & 366 & .11 & .000 \\
\hline Toplam & 58.36 & 370 & & \\
\hline
\end{tabular}

Tablo 8'e göre, ilahiyat fakültesinde öğrenim görmekte olan öğrencilerin epistemolojik inançları, sınıf düzeyine dayalı olarak karşılaştırıldığında anlamlı düzeyde farklılık göstermektedir $\left[\mathrm{F}_{(4,366)}=36.37, p=.000\right]$. Tukey testi sonuçları incelendiğinde, hazırlık sınıfındaki ve 1 . sinıftaki öğrencilerin epistemolojik inançlarının 2, 3 ve 4. sınıf öğrencilerinin epistemolojik inançlarından anlamlı düzeyde düşük olduğu tespit edilmiştir.

\section{Sonuç ve Öneriler}

İlahiyat fakültesinde öğrenim görmekte olan öğrencilerin epistemolojik inanç düzeyleri verilen değişkenlere (sınıf, yaş, cinsiyet) göre anlamlı farklılık göstermektedir. Kadın öğrenciler, erkek öğrencilere göre epistemolojik inanç düzeyinde daha yüksek puanlara sahiptir. Bu sonuçta grubun çoğunluğunun kadın öğrencilerden oluşması etkili olmuştur. Ülkemizde kadın bireyler erkek bireylere göre hem dini konularda daha çok hassasiyet göstermekte hem de dini eğitim almak ve din hakkında yeni bilgiler öğrenmek konusunda daha önde yer almaktadırlar (Gök, Carlos, Rabo, 2011). İlahiyat fakültelerinde de bu durum geçerliliğini korumaktadır. Nitekim ilahiyat fakültelerinin genel olarak öğrenci dağılımına bakıldığında kadın öğrencilerin erkek öğrencilerden sayıca fazla olduğu görülmektedir. Bu etkilerle birlikte, kadın öğrencilerin epistemolojik inanç düzeyleri, erkek öğrencilerin epistemolojik inanç düzeylerinden yüksek çıkmıştır.

Yapılan araştırma sonucunda ilahiyat fakültesinde öğrenim görmekte olan öğrencilerin okula başladıkları hazırlık sınıfındaki öğrenmeye yönelik epistemolojik inanç düzeyi ile ilerleyen sınıflardaki öğrenmeye yönelik epistemolojik inanç düzeyleri arasında anlamlı bir fark bulunmuştur. Diğer bir ifadeyle hazırlık sınıfina başlayan öğrencilerin öğrenmeye karşı 
epistemolojik inanç düzeyleri, ilerleyen sınıflardaki öğrencilerin öğrenmeye yönelik epistemolojik inanç düzeylerinden düşük bulunmuştur. Bu durum göstermektedir ki ilahiyat fakültesinde verilen eğitim, ilahiyat fakültesi öğrencilerinin öğrenmeye yönelik epistemolojik inanç düzeylerinin artması yönünde katkı sağlamaktadır.

Tablo 5'te gösterilen analiz sonuçlarında ise öğrencilerin yaşları ile öğrenmeye karşı epistemolojik inançları arasında anlamlı farklar olduğu tespit edilmiştir. Analiz sonuçlarına göre; 18 yaş ve 30 yaş öğrencilerin öğrenmeye yönelik epistemolojik inanç düzeyleri daha düşükken, diğer yaş aralığındaki öğrencilerin öğrenmeye yönelik epistemolojik inanç düzeyleri daha yüksek tespit edilmiştir.

18 yaş öğrencileri genel olarak okula yeni başlayan hazırlık sınıfi öğrencilerinden oluşmaktadır. Tablo 7'de öğrencilerin öğrenmeye yönelik epistemolojik inanç düzeyleri sınıf düzeyine göre analiz edilmiş ve sonuçları verilmiştir. Burada hazırlık sınıfı öğrencilerinin öğrenmeye yönelik epistemolojik inanç düzeylerinin düşük olduğu tespit edilmiş ve bunda öğrencilerin ilahiyat fakültesindeki eğitimlerine yeni başlamış olmalarının etkili olabileceği değerlendirilmiştir.

30 yaş ve üzeri öğrencilerin öğrenmeye yönelik epistemolojik inanç düzeylerinin diğer yaş gruplarına göre düşük olmasının nedeni ise kuşaklar teorisi ile açıklanabilir. Bu bağlamda şunu ifade edelim ki geçmişten günümüze dünya da hemen her konuda değişim ve ilerleme gözlemlenmektedir. Bu değiş̧im ve ilerlemenin en büyük kaynağı insan olduğu gibi, bu değişim ve ilerlemenin sonuçlarından en çok etkilenen de yine insandır. İnsanoğlunu en derinden etkileyen değişim ve ilerlemelerden biri sanayi devrimidir. Sanayi devrimi, bilgi toplumuna geçiși sağlamıș ve toplumlar yeni bir boyut kazanmıştır (Sütçü ve Akyazı'dan aktaran Taşpınar ve Tuncer, 2008). Bilgi toplumuna geçişle birlikte teknolojik çalışmalar yapılmış ve teknoloji günden güne hızlı gelişimini sürdürmüştür. Böylece insanların isteklerinde, arzularında, ihtiyaçlarında, davranış biçimlerinde ve genel manada yaşamlarında değişikliklere yol açmıştır (Yelkikalan, Akatay, \& Altın, 2010). Belli değişiklikleri aynı anda yaşayan insanlar benzer özellikleri göstermeye başlamış ve böylece kuşaklar ortaya çıkmıştır. Kuşaklar; sessiz kuşak, bebek kuşağı, X kuşağı, Y kuşağı ve Z kuşağı olarak sıralanmaktadır (Taşlıbeyaz, 2019). Y kuşağı 1980-1999 yılları arasında doğan, teknoloji ile doğan, teknolojiyi kullanabilen kuşaktır (Kyles, 2005). Prensky (2001) bu kuşağı "dijital yerliler" olarak tanımlamaktadır. Bu kuşak X kuşağ1 ile Z kuşağı arasında köprü görevi kurmaktadır. Y kuşağ1 teknoloji ile doğmuş ve bunun avantajlarını görmüş olmanın etkisiyle sabırsızdır. Teknolojiden yararlanmalarına rağmen yine de yüz yüze görüşmeleri tercih ederler. Yüksek otorite ve hiyerarşiden nefret ederler. Girişimci özelliktedirler ve işlerinin patronu olmak isterler. Araştırmamız nedeniyle en önemli özelliklerinden biri eğitime önem verirler ve hizmet içi eğitim alma konusunda üst düzeyde katılım gösterirler. Z kuşağ 2000 yılı ve sonrasını kapsayan nesildir. Diğer adıyla "dijital kuşaktır" ( Prensky, 2001). Dijital kuşak Y kuşağından çok daha fazla oranda teknoloji ile iç içedir ve teknolojinin hızından yararlanan kuşak olarak çok daha sabırsızdırlar. Yüz yüze görüşmeler yapmak yerine daha çok online görüşmeler yapmak isterler. Teknolojinin onlara sunduğu avantajları aşırı derecede benimsemişlerdir. $\mathrm{Bu}$ durum, bireyselliğe tam anlamıyla adapte olmuş bu kuşağın en büyük probleminin ilerde yalnızlık olacağı tahmin edilmektedir (Çamsarı, 2013, s.26). Konumuz kapsamında bu kuşağın en önemli özelliği eğitim konusunda Y kuşağı kadar istekli değildir ve teknolojinin etkisiyle değişikliklere açık, her an değişim olabileceğinin farkındadırlar. Kısaca araştırma çalışma grubumuzda bulunan 30 yaş öğrencileri Y kuşağını temsil ederken, diğer yaş grubundaki öğrenciler Z kuşağını temsil eder. Bu durum bu iki grup arasında bilgiye bakış açılarının farklı olmasının en büyük sebeplerinden biri olabilir. 30 yaş üzeri grup böylece eğitime daha çok önem verip $\mathrm{Z}$ gurubuna göre değişikliğe daha kapalıyken, diğer yaş grubundaki öğrenciler için değişiklik zaten hayatın kendisidir. Değişikliğe açık olmaları onların epistemolojik inanç düzeyleri üzerinde etkili olmaktadır. Epistemolojik inanç düzeyi yüksek olan bireyler değişikliğe daha açiktırlar. Tüm bunlar bireylerin bilgiye olan bakış açılarını da etkilemiş, 30 yaş üzeri bireylerin öğrenmeye yönelik epistemolojik inanç düzeyleri 
daha düşük çıkarken diğer yaş gruplarında bulunan öğrencilerin öğrenmeye yönelik epistemolojik inançları daha yüksek bulunmuştur. Bu durum göstermektedir ki yaşla bitlikte bireyin bulunduğu dijital kuşakta epistemolojik inanç düzeyi üzerinde etkili olmaktadır.

İlahiyat fakültesi öğrencilerinin öğrenmeye yönelik epistemolojik inançları ile ilgili daha önce yapılmış bir çalışma bulunmamaktadır. Fakat Kutluca, Soysal ve Radmard (2018) tarafından eğitim fakültesinde öğrenim görmekte olan 375 öğretmen adayı üzerinde yaptıkları çalışma ile bu fakültede öğrenim görmekte olan öğrencilerin öğrenmeye yönelik epistemolojik inanç düzeylerini tespit etmişlerdir. Yapmış oldukları araştırma sonuçlarına göre, öğrencilerin öğrenim gördükleri sınıf düzeyleri ile öğrenmeye yönelik epistemolojik inanç düzeyinde anlamlı bir fark bulunmazken, araştırmamızda hazırlık sınıfları ile daha üst sınıflardaki öğrencilerin öğrenmeye yönelik epistemolojik inançları arasında anlamlı bir fark bulunmuştur. Kutluca, Soysal ve Radmard (2018) öğrencilerin yaşları ile öğrenmeye yönelik epistemolojik inançları arasında anlamlı bir ilişki bulunmuştur. Yapmış olduğumuz araştırmanın da öğrencilerin yaşları ile öğrenmeye yönelik epistemolojik inançları arasında anlamlı bir fark olduğunu tespit etmesi bu iki araştırmanın bu konuda birbirine paralel olduğunu göstermektedir. Yine öğrencilerin cinsiyetleri ile öğrenmeye yönelik epistemolojik inanç düzeyleri arasında anlamlı bir fark bulunmuş ve bu açıdan birbiri ile paralel sonuçlara ulaşılmıştır. Yenice, Alpak Tunç ve Yavaşoğulu (2018) tarafindan orta öğretim öğrencilerinin epistemolojik inançların incelenmesi amacıyla yapılan araştırmada öğrencilerin cinsiyetleri ile epistemolojik inançları arasında anlamlı farklar bulunurken, sınıf düzeyleri ile epistemolojik inançları arasında herhangi bir fark bulunmamıştır. Cinsiyet değişkeni açısından anlamlı fark bulunması yapmış olduğumuz araştırmayı destekler niteliktedir. Akmençe, Kuloğlu ve Akpınar (2016) tarafından pedagojik formasyon öğrencilerinin epistemolojik inançları ile ilgili yapılan araştırmada öğrencilerin epistemolojik inançları ile cinsiyetleri arasında anlamlı farklar olduğu bulunmuştur. $\mathrm{Bu}$ araştırma sonucu ile yapmış olduğumuz araştırma sonucunun paralel olduğu görülmektedir. Yapılan benzer araştırmalardan ve yapmış olduğumuz araştırma bulgularından hareketle şu öneriler sunulmuştur;

1. Ö Ögrencilerinin öğrenme şekilleri ve öğrenmeye olan bakış açıları, onlara sunulacak dersin yöntem, strateji ve dersin işlenmesi üzerinde etkili olmaktadır. Bu araştırma sonuçları da kullanılarak ilahiyat fakültesi öğretim üyelerinin derste kullanacakları öğretim yöntem ve tekniklerinin ve tasarlanmak istenen yeni ögretim yöntem ve tekniklerinin, materyal tasarımının neler olabileceği araştırılabilir.

2. İlahiyat fakültesi öğretim üyelerinin dersi işlemelerine yönelik tutumları araştırılabilir.

3. İlahiyat fakültesi öğrencilerinin öğrenmeye yönelik epistemolojik inançlarına bağlı olarak, hazırlanan ve sunulan programda öğrenci ihtiyaçlarında ve öğrenci profilinde değişiklik veya yeniden yapılandırılmaya gidilebilir. Bu doğrultuda öğrencilerin ilahiyat fakültesi müfredat ve programına yönelik görüşleri alınabilir.

4. Araştırmamızda yalnızca ilahiyat fakültesi öğrencileri çalışma grubu olarak alınmıştır. Diğer fakülteler ile birlikte yapılacak bir çalışma ile bu fakültelerin epistemolojik inanç düzeylerine yönelik sonuçları karşılaştırılabilir.

\section{Kaynakça}

Başbay, M., (2013). Epistemolojik inancın eleştirel düşünme ve üst biliş ile ilişkisinin yapısal eşitlik modeli ile incelenmesi. Eğitim ve Bilim. 38 (169), 250-262.

Çamsarı, U.M. (2013). z kuşağı çocukları. Genç Haber Dergisi, (1), 26-28. 
Demir, S. \& Akınoğlu, Ö. (2010). Epistemolojik inanışlar ve öğretme öğrenme süreçleri. M.Ü. Atatürk Eğitim Fakültesi Eğitim Bilimleri Dergisi, 32, 75 - 93.

Deryakulu, D. \& Şener Büyüköztürk. Ş. (2005). Epistemolojik inanç ölçeğinin faktör yapısının yeniden incelenmesi: cinsiyet ve öğrenim görülen program türüne göre epistemolojik inançların karşılaştırılması. Eurasian Journalof Educational Research, 18, (57-70).

Demir, Ö. (2009). Bilişsel koçluk yöntemiyle ögretilen bilişsel farkındalık stratejilerinin altıncı sınıf sosyal bilgiler dersinde ögrencilerin epistemolojik inançlarına, bilişsel farkındalık becerilerine, akademik başarılarına ve bunların kalıcılıklarına etkisi. (Yayımlanmamış Doktora Tezi), Çukurova Üniversitesi Sosyal Bilimler Enstitüsü.

Gök. F., Rabo. A., \& Carlos. M. (2011). Çokkültürlü toplumlarda eğitim türkiye ve isveç’ten örnekler (1. Baskl). Bilgi Üniversitesi.

Karasar, Niyazi. (1999). Bilimsel araştırma yöntemlerinde kavramlar, ilkeler, teknikler, (9. Bask1). Nobel Yayın Dağıtım.

Kutluca, A. Y., Soysal, Y., \& Radmard, S. (2018). Öğrenmeye yönelik epistemolojik inançlar ölçeğinin uygulamalı uyarlama ve güvenirlik çalışması. Eğitimde Kuram ve Uygulama, 14 (2), 129-152.

Kuloğlu, A., Akpınar, B. \& Akmençe, E. (2016). Pedagojik Formasyon Öğrencilerinin Epistemolojik İnançlarının Cinsiyet $\mathrm{Ve}$ Branş Değişkenine Göre İncelenmesi.VII. Uluslararası Eğitim Araştırmaları Kongresi.

Kyles, D. (2005), Managing your multigenerational workforce, Strategic Finance, 87(6), 52-55.

Milli Eğitim Bakanlığı, (2010). İlköğretim Din Kültürü ve Ahlak Bilgisi Öğretim Programı. Devlet Kitapları Müdürlüğü

Prensky, M. (2001). Digital natives, digital immigrants part 1. On the Horizon, 9 (5), 1-6.

Schommer, M. (1990). Effects of beliefs about the nature of knowledge on comprehension. Journal of Educational Psychology, 82 (3), 498-504.

Schommer, M., \& Walker, K. (1997). Epistemological beliefs and valuing school: considerations for college admissions and retention. Research in Higher Education. 38, 173-186.

Sing-Chai, C., Teo, T., \& Beng-Lee, C. (2009). The change in epistemological beliefs and beliefs about teaching and learning: a study among pre-service teachers. Asia-Pacific Journal of Teacher Education, 37 (4), 351-362.

Taşlıbeyaz, E. (2019). Z kuşağı ile ilgili araştırma eğilimlerinin ve eğitime yönelik katkılarının analizi. Sosyal Bilimler Enstitüsü Dergisi, 21 (3), 715-729.

Taşpınar. M., \& Tuncer. M. (2008). Sanal ortamda eğitim ve öğretimin geleceği ve olası sorunlar. Sosyal Bilimler Dergisi, Sayı 20,

Turan, İ., Şimşek, Ü., \& Aslan, H. (2015). The use and analysis of likert scales and likert-type 1tems in educational research. Sakarya Üniversitesi Eğitim Fakültesi Dergisi, 0 (30), 186203.

Topcu, M. S. (2011). Turkish elementary student teachers' epistemological beliefs and moral reasoning. European Journal of Teacher Education, 34 (1), 99-125.

Yelkikalan, N., Akatay, A., \& Altın, E. (2010). Yeni girişimcilik modeli ve yeni nesil girişimci profili: internet girişimciliği ve y, m, z kuşağı girişimciliği. Sosyal Ekonomik Araştırmalar Dergisi, 10 (20), 489-506. 
Yenice, N. \& Alpak, Tunç, G., \& Yavaşoğlu, N. (2018). Ortaöğretim öğrencilerinin bilimsel epistemolojik inançlarının incelenmesi. Mehmet Akif Ersoy Üniversitesi Eğitim Fakültesi Dergisi. 45 (132-15).

Yıldırım, A., \& Şimşek, H. (2008). Sosyal Bilimlerde Nitel Araştırma Yöntemleri (6. Baskı), Seçkin.

Yıldırım, A. (1999). Nitel araştırma yöntemlerinin temel özellikleri ve eğitim araştırmalarındaki yeri ve önemi. Eğitim ve Bilim, 23, Sayı 112, 